Edukatif : Jurnal Ilmu Pendidikan Volume 1 Nomor 3 Tahun 2019 Halaman 150-156

EDUKATIF: JURNAL ILMU PENDIDIKAN

Research \& Learning in Education

https://edukatif.org/index.php/edukatif/index

\title{
PENGARUH BAHAN AJAR TEMATIK TERPADU TERHADAP IDENTITAS BANGSA SISWA SEKOLAH DASAR
}

\author{
Fatma Khaulani ${ }^{1}$, Firman ${ }^{2}$ \\ Universitas Negeri Padang, Sumatera Barat, Indonesia ${ }^{1,2}$ \\ e-mail : fatmakhaulani25@gmai.com¹, firman@konselor.org ${ }^{2}$
}

\begin{abstract}
Abstrak
Tujuan - untuk melihat pengaruh penggunaan bahan ajar tematik terpadu pada peningkatan identitas bangsa siswa SD melalui tes. Metodologi - penelitiannya adalah penelitian quasi eksperimen. Hasil akhir didapatkan kelas eksperiment rata-rataanya 78,182 serta kontrl 67,727. Hasil penelitian menunjukkan bahwa data berdistribusi normal serta homogen kemudiaan nilai perhitungan uji-t didapatkan $t_{\text {hitung }} 2,434$ dan $\mathrm{tt}_{\text {abel }} 2,020$ ini artinya $t_{\text {hitun }} \mathrm{g}>\mathrm{tt}_{\mathrm{abel}}$, terjadi penerimaan $\mathrm{Ho}_{\mathrm{o}}$ ditolak serta diterimanya $\mathrm{H}_{1}$. Implikasi, disimpulkan bahwasanya penggunaan bahan ajar tematik terpadu berdampak kepada identittas bangsa siswa kelas V SD.
\end{abstract}

Kata Kunci: Bahan Ajar, Tematik Terpadu, Identitas Bangsa

\begin{abstract}
Objective - to see the effect of the use of integrated thematic teaching materials on improving the national identity of elementary school students through tests. Methodology - the research is quasi-experimental research. The final results obtained an average experimental class 78.182 and 67.727 controls. The results showed that the data were normally distributed and homogeneous, then the t-test calculation values obtained t- count 2.434 and ttable 2.020, this means t-count $>\mathrm{t}$-table, the acceptance of Ho was rejected and the receipt of $\mathrm{H} 1$. Implications, it is concluded that the use of integrated thematic teaching materials has an impact on the national identity of fifth gradeelementaryschool students.
\end{abstract}

Keywords: Teaching Materials, Integrated Thematic, National Identity

@Edukasi: Jurnal Ilmu Pendidikan FIP UPTT 2019

$\triangle$ Correspondingauthor:

Address : Jl. Perkutut No 8 Padang, Sumatera Barat

Email : fatmakhaulani25@gmail.com

ISSN 2656-8063 (Media Cetak)

Phone

ISSN 2656-8071 (Media Online) 


\section{PENDAHULUAN}

Globalisasi merupakan suatu fenomena yang marak terjadi akhir-akhir ini. Apalagi setelah dunia memasuki revolusi industri 4.0. Batas wilayah tidak lagi menjadi penghalang bagi generasi milenial saat ini untuk dapat melakukan berbagai aktivitas. Pergaulan antar bangsa menjadi semakin kental yang mangakibatkan terjadinya proses alkulturasi budaya, saling meniru dan saling mempengaruhi antara budaya masing-masing menjadi hal yang lazim. proses akulturasi dapat memberikan dampak negatif seperti terkikisnya nilai-nilai di dalam masyarakat. Jika hal ini tidak dapat dibendung maka dapat mengganggu ketahanan di segala aspek bahkan mengarah kepada terkikisnya identitas bangsa. Era globalisasi juga memberi pengaruh terhadap hilangnya nilai budaya bangsa. Masyarakat menjadi kehilangan rasa bangga terhadap bangsa sendiri. Siwa sekolah dasar yang notabenenya merupakan generasi penerus bangsa tidak luput dari serangan fenomena. Siswa SD sudah mulai tidak mengenali ciri khas bangsanya karena sudah terpengaruhi budaya lain. Siswa SD lebih menyenangi budaya luar dibanding budanya sendiri dan sudah hilangnya rasa bangga terhadap bangsa sendiri yang mengakibatnya timbulnya krisis identitas bangsa. Hal ini tampak pada fenomena yang dapat diamati saat ini, anak SD saat ini lebih menyenangi makanan fast food seperti KFC, CFC, pizza yang notabene nya bukan merupakan makanan dari Indonesia ketimbang makanan khas bangsa kita sendiri. Selain itu dari segi hiburan juga memberi peran yang signifikan bagi siswa. Saat ini terlihat siswa SD lebih menyenangi acara tontonan kartun seperti Upin dan Ipin di televisi dianggap lebih menarik dibandingkan kartun Unyil yang merupakan karya anak bangsa.

Penelitian yang dilakukan oleh Parji (2011) mengungkapkan bahwa, dunia pendidikan mempunyai peranan yang sangat penting dalam mengembangkan nilai-nilai identitas nasional saat ini. Pada saat ini peranan guru sangat diperlukan untuk menguatkankan identitas nasional siswa. Oleh karena itu, setiap guru hendaknya dapat memiliki kompetensi yang baik dan komprehensif dalam menjalankan upaya peningkatan identitas nasional ini. Dari penelitian tersebut tampak bahwa upaya mempertahankan identitas nasional siswa dapat dilakukan dengan pendidikan melalui peranan guru. Oleh sebab itu perananan pendidikan serta guru sangat diperlukan dalam mengatasi permasalahan ini.

Pendidikan merupakan usaha sadar dan terencana untuk mewujudkan suasana belajar dan proses pembelajaran agar peserta didiksecara aktif mengembangkan potensi dirinya untuk memiliki kekuatan spiritual keagamaan, pengendalian diri, kepribadian, ilmu pengetahuan, moral, serta skill yang dibutuhkan dalam masyarakat (Sisdiknas, 2003). Pendidikan sebagai gerbang utama dalam menghadapi pesatnya perubahan zaman mengalami perkembangan dari waktu ke waktu yang senantiasa memerlukan peningkatan mutu. Upaya yang telah dilakukan pemerintah untuk meningkatkan mutu pendidikan saah satunya dengan dikeluarkannya Undang-Undang tentang Sistem Pendidikan Nasional pada tahun 2003, di mana pengembangan kurikulum 2013 dilakukan sebagai penyempurnaan Kurikulum Tingkat Satuan Pendidikan (KTSP) tahun 2006 yang dikenal dalam pembelajaran tematik terpadu. Pembelajaran tematik terpadu merupakan pembelajaran yang mengintegrasikan berbagai KD dari beberapa mata pelajaran ke dalam berbagai tema sehingga pembelajaran tersebut dapat memberikan pengalaman berarti kepadasiswa . Di samping itu, pembelajaran tematik terpadu memberikan pengalaman belajar yang menyenangkan karena relevan dengan kehidupan peserta didik.

Edukasi : Jurnal Ilmu Pendidikan Vol 1 No 3 Tahun 2019 p-ISSN 2656-8071 e-ISSN 2656-8063 
Insan Indonesia yang produktif, inovatif serta kreatif dapat dihasilkan dari pengembangan kurikulum 2013 melalui penguatan sikap, keterampilan serta pengintegrasian pengetahuan (Mulyasa, 2013). Melihat pentingnya pengembangan kurikulum 2013 ini, guru hendaknya mampu merancang dan mempersiapkan berbagai kebutuhan dalam menunjang pembelajaran dengan baik serta memperhatikan kebutuhan setiap siswa salah satunya bahan ajar.

Bahanajar merupakan seperangkat bahan yang berisikan materi baik secara tertulis maupun tidak yang telah disusun oleh guru secara sistematis yang berguna dalam proses pembelajaran bagi siswa untuk menciptakan suasana atau kondisi belajar yang kondusif. (Daryanto dan Dwicahyono, 2014).

Bahanajar memiliki beberapa jenis setiap jenis bahan ajar memiliki ciri khas atau karakteristik yang membedakan satu dengan yang lainnya. Bahan ajar tersebut dibedakan menjadi : (1) cetak (printed) (2) program audio (3) audio visual, (Majid, 2012).

Bahan ajar memberikan manfaat pada proses pembelajaran. Bagi guru bahan ajar sesuai dengan tuntutan capaian yang diharapkan oleh kurikulum, bukan tergantung pada buku teks yang disedikan oleh pemerintah saja. Sedangkan bagi siswa bahan ajar memberikan manfaat menumbuhkan motivasi siswa dalam belajar, pembelajaran yang dialami oleh siswa

menjadi lebih menarik serta siswa mudah untuk memahami materi setiap indikator yang diberikan oleh guru. (Prastowo, 2012)

Bahan ajar memiliki karakteristik yaitu: (1) Self intructional. (2) Stand alone. (3) Adaptive (4) User friendly (Kantun dan Budiawati, 2015).

Berdasarkan uraian diatas, peneliti tertarik untuk meneliti mengenai pengaruh penggunaan bahan ajar tematik terpadu terhadap peningkatan identitas bangsa di SD melalui tes dengan menggunakan bahan ajar cetak berbentuk buku yang berisikan materi kelas $\mathrm{V}$ tema 5 yaitu Bangga Sebagai Bangsa Indonesia, sub tema 2 Indonesiaku, Bangsa berbudaya. Dengan menggunakan bahan ajar akan melihat bagaimanakah peningkatan identitas bangsa siswa kelas V di SD ini yang dilihat dati hasil tes belajar siswa. Pembahasan ini ditujukan agar dapat memberikan informasi dan rekomendasi kepada pendidik dalam melakukan upaya peningkatan identitas bangsa melalui proses pembelajaran dapat memberikan hasil yang optimal

\section{METODE}

Kajian iniadalah penelitian eksperimen menggunakan desaign Quasi eksperimental research. Rancangan ini terdiri dua kelompok subjek yang sama-sama mendapat perlakuan namun tiap kelompok mendapatkan perlakuan yang berbeda. Kelompok yang pertama $\left(\mathrm{O}_{1}\right.$ dan $\mathrm{O}_{2}$ ) mendapat perlakuan dengan proses pembelajaran menggunakan bahan ajar tematik. Sedangkan kelompok yang kedua $\left(\mathrm{O}_{3}\right.$ dan $\left.\mathrm{O}_{4}\right)$ tidak mendapatkan perlakuan sama sekali, yang mana proses pembelajaran menggunakan model konvensional.

Adapun tahapan dalam mewujudan desain penelitian terlihat dari bagan berikut: 


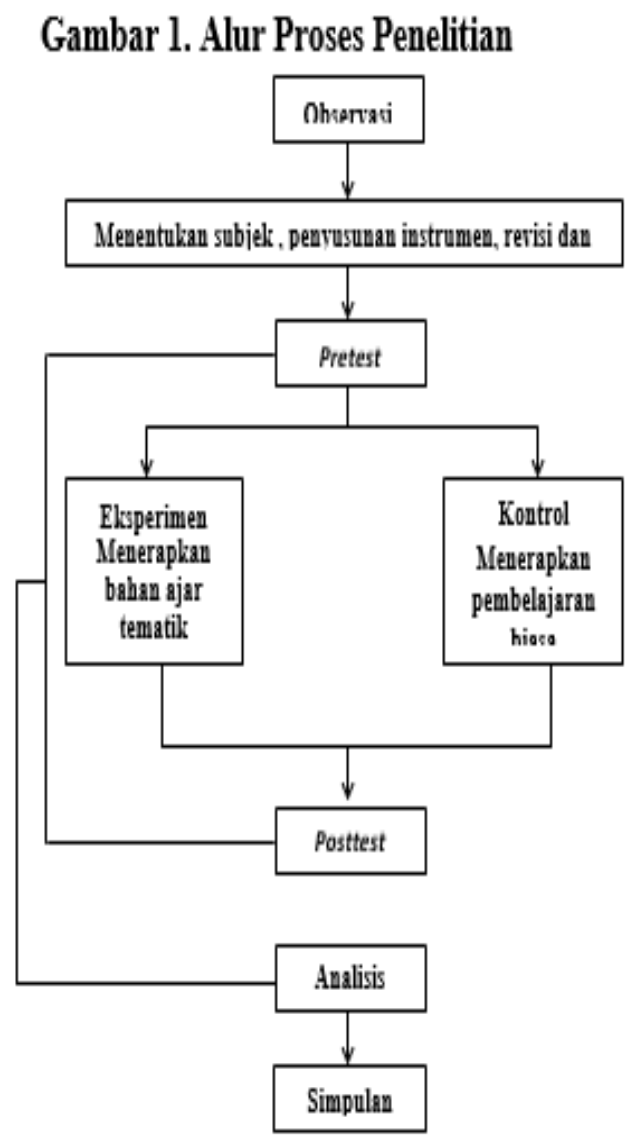

\section{Tempat dan Waktu Penelitian}

Pada penelitian ini jumlah siswa kelas V SD negeri 20 Indarung 44 orang. Subjek pada penelitian ini ialah siswa kelas VA dan VB dengan kelas VA sebanyak 22 siswa sedangkan kelas VB yang berjumlah 22 siswa. Pada saat menentukan kelas eksperimen dan kelas kontrol pada penelitian ini digunakan teknik random sampling, yaitu pengambilan sampel secara acak dengan menggunakan undian. Maka sampel pada penelitian ini dipilih secara acak. Jadi dalam penelitian ini yang menjadi kelas kontrol adalah VA dan kelas eksperimen adalah VB. Adapun penetapan kelas eksperimen dan kelas kontrol dipilih berdasarkan pencabutan undian oleh wali kelas VA dan VB.

\section{Variabel Penelitian}

Variabel dalam Penelitian ini adalah:

Variabel bebas yaitu bahan ajar tematik terpadu (X). Variabel terikat yaitu identitas bangsa siswa (Y) Penentuan kelas kontrol serta kelas eksperimen menggunakan teknik random sampling, yaitu sampel diambil secara acak dengan diundi. Didapatkan kelas VA selakukontrol dan kelas eksperimennyaadalah VB.

Tahapan pelaksanaan dalampengukuran variabel ini pada kelasa kontrol dan eksperimen adalah sama, yaitu:

a. Memberikan prettest. Soal prettest berguna untuk mengetahui pemahan siswa mengenai suatu materi yang akan dipelajari. Soal tes awal yang diberikan berupa soal objektif sebanyak 20 soal.

b. Penyampaian materi. Kelompok eksperimen penyampaian materi dengan bahan ajar tematik terpadu, sedangkan di kelompok kontrol diajarkan dengan metode ceramah.

c. Memberikan posttest. Hal tersebut untuk mengetahui hasil akhir siswa setelah diberikan bahan ajar tematik terpadu, pada kelas ekspermen dan metode cerammah biasa pada kelas kontrol. Soalnyaberjumlah 20 buah berupa soal objektif.

\section{Deskripsi Pelaksanaan Pada Kelas Eksperimen}

Peneliti memperkenalkan diri terlebih guna menginformasikan tujuan penelitian tersebut kepada siswa kelas VB. Setelah memperkenalkan diri dan memberi tahu maksud dan tujuan peneliti kepada siswa. Pertemuan pertama di awali dengan memberikan tes awal (pretest) kepada kelas ekperimen (VB), junlah siswa yang hadir pada saat di berikan test awal berjunlah 22 orang siswa. Soal tes awal yang diberikan berupa soal objektif sebanyak 20 soal. Siswa mengerjakan pretest sesuai dengan apa 
yang mereka ketahui dan menyelesaikannya tepat pada waktu yang telah di tentukan.

Pertemuan dilaksanakan selama 2 jam pembelajaran ( 2 x 35 menit) pada jam kedua siswa yang hadir berjumlah 22 orang siswa. Pada pertemuan ini peneliti memberi bahan ajar tematik terpadu yang disediakan sebelumnya.

Pertemuan terakhir di kelas eksperiment memberikan soal posttest atau tes akhir. Untuk melihat kemampuan akhir peserta didik sesudah dilakukan pembelajaran dengan menggunakan bahan ajar tematik terpadu. Soal posttest merupakan soal objektif yang berjumlah 20 soal berbeda dari soal pra tes sebelumnya.

\section{Pelaksanaan Pembelajaran Pada Kelas Kontrol}

Sebelum memberikan tes awal kepada siswa, peneliti memperkenalkan diri terlebih menjelaskan maksud dan tujuan penelitian tersebut kepada siswa kelas VB. Setelah memperkenalkan diri dan memberi tujuan peneliti kepada siswa. Pertemuan pertama di awali dengan memberikan pretest kepada kelas kontrol (VA), junlah siswa yang hadir pada saat di berikan test awal berjunlah 22 orang siswa. Soal tes awal yang diberikan berupa soal objektif sebanyak 20 soal. Siswa mengerjakan pretest sesuai dengan apa yang

mereka ketahui dan menyelesaikannya tepat pada waktu yang telah di tentukan.

Pertemuan menyampaikan materi. Pertemuan dilaksanakan selama 2 jam pembelajaran $(2 \times 35$ menit) pada jam kedua siswa yang hadir berjumlah 22 orang siswa. Pada pertemuan ini peneliti memberi materi menggunakan bahan ajar tematik terpadu dengan hanya menggunakan metode ceramah saja.

Pertemuan terakhir di kelas kontrol yaitu dengan pemberian soal posttest guna mengetahui kemampuan siswa setelah dilakukan pembelajaran dengan menggunakan bahan ajar tematik terpadu. Soal uji akhir berupa soal objektif yang berjumlah 20 soal berbeda dari soal pretest yang sudah diberikan pada pertemuan pertama.

\section{HASIL DAN PEMBAHASAN}

\section{A. Hasil data tes}

Data yang di deskripsikan disini merupakan data hasil pretest dan posttest dari kedua kelas. Data yang digunakan dalam penelitian ini berupa data kuantitatif berupa tes objektif.

Tabel 2. Rekapitulasi Hasil Pretest Hasil Belajar Kelas Eksperimen dan Kelas Kontrol

\begin{tabular}{lcccc}
\hline Kelas & $\begin{array}{c}\text { Jumlah } \\
\text { Siswa } \\
(\mathrm{n})\end{array}$ & $\begin{array}{c}\text { Rata- } \\
\text { rata } \\
(X)\end{array}$ & $\begin{array}{c}\text { Standar } \\
\text { Deviasi } \\
(\mathrm{s})\end{array}$ & $\begin{array}{c}\text { Varians } \\
\left(s^{2}\right)\end{array}$ \\
\hline Eksperimen & 22 & 49,545 & 11,434 & 130,736 \\
\hline Kontrol & 22 & 52,500 & 11,207 & 125,5968 \\
\hline
\end{tabular}

Berdasarkan data tersebut dapat dilihat bahwa terdapat perbedaan rata-rata skor pretest antara kelas eksperimen dengan kelas kontrol. Kemudian hasil post-test untuk kelas eksperimen dan kelas kontrol dapat dilihat di bawah ini :

Tabel 3 Rekapitulasi Hasil Posttest Hasil Belajar Analisis Hasil Tes

\begin{tabular}{ccccc}
\hline Kelas & $\begin{array}{c}\text { Jumlah } \\
\text { Siswa } \\
(\mathbf{n})\end{array}$ & $\begin{array}{c}\text { Rata- } \\
\text { rata } \\
(\boldsymbol{x})\end{array}$ & $\begin{array}{c}\text { Standar } \\
\text { Dexiasi } \\
(\mathbf{s})\end{array}$ & $\begin{array}{c}\text { Varians } \\
\left(\boldsymbol{s}^{\mathbf{2}}\right)\end{array}$ \\
\hline Eksperimen & 22 & 78,182 & 8,937 & 79,869 \\
\hline Kontrol & 22 & 67,727 & 10,204 & 104,121 \\
\hline
\end{tabular}

\section{Normalitas}

Pada uji normalitas dalam penelitian ini menggunakan uji liliefors. Berdasarkan uji normalitas kelas eksperimen dan kelas kontrol diperoleh $\mathrm{L}_{0}$ dan $\mathrm{L}_{\text {tabel }}$ pada taraf nyata $\alpha=0,05$ seperti terlihat pada tabel di bawah ini: 
Tabel 4. Hasil Uji Normalitas Akhir

\begin{tabular}{ccccc}
\multirow{2}{*}{ Kelas } & \multicolumn{3}{c}{ Normalitas } & Keputusan \\
\cline { 2 - 4 } & $\mathrm{N}$ & $L_{\text {maks }}$ & $L_{\text {tabel }}$ & \\
\hline Eksperimen & 22 & 0,101 & 0,183 & Normal \\
\hline Kontrol & 22 & 0,102 & 0,1883 & Normal \\
\hline
\end{tabular}

Sumber: Data Post Test

Dari Tabel 4 terlihat bahwa kelas eksperimen dan kelas kontrol memiliki $\mathrm{L}_{0}<\mathrm{L}_{\text {tabel. }}$ Berdasarkan hal tersebut dapat disimpulkan bahwa kedua kelas sampel berdistribusi normal

\section{Uji Homogenitas}

Uji homogenitas bertujuan untuk mengetahui kelas eksperimen dan kelas kontrol memiliki varians yang homogen/tidak. Uji yang digunakan adalah uji F. Analisis homogenitas sampel dapat dilihat sebagai berikut:

Tabel 5. Hasil Uji Homogenitas Akhir

\begin{tabular}{lllll}
\hline \multirow{2}{*}{ Kelas } & \multicolumn{3}{c}{ Homogenitas } & Keputusan \\
\cline { 2 - 3 } & Varians & $\mathrm{F}_{\text {hitung }}$ & $\mathrm{F}_{\text {tabel }}$ & \\
\hline Eksperimen & 79,870 & \multirow{2}{*}{1,3035} & 2,095 & Homogen \\
\hline Kontrol & 104,112 & & & \\
\hline
\end{tabular}

Berdasarkan tabel 5 di atas dapat diketahui bahwa uji homogenitas skor tes akhir siswa kelas eksperimen dan kelas kontrol dengan taraf signifikan $\mathrm{a}=0,05$; memenuhi kriteria $\mathrm{F}_{\text {hitung }}<$ $\mathrm{F}_{\text {tabel }}$ atau 1,3035 2,095 artinya bahwa varians kelas ekperimen dan kelas kontrol bersifat homogen.

\section{Uji t}

Untuk menguji hipotesis digunakan uji-t ( $t$ test).

Dari hasil uji hipotesis dengan menggunakan $t$-test tersebut dapat diperoleh hasil sebagai berikut:
刺 Tabel 6. Hasil Ujit

\begin{tabular}{|c|c|c|c|c|c|}
\hline \multirow{2}{*}{ Kelas } & \multicolumn{4}{|c|}{ Ujit } & \multirow{2}{*}{ Keputusa: } \\
\hline & $\bar{x}$ & S & $t_{\text {hitung }}^{\prime}$ & $t_{\text {tabel }}^{\prime}$ & \\
\hline Eksperimen & 0,593 & 0,118 & \multirow[t]{2}{*}{2,434} & \multirow[t]{2}{*}{2,0200} & \multirow{2}{*}{$\begin{array}{l}\text { Terdapat } \\
\text { perbedaar } \\
\text { yang } \\
\text { signifikar }\end{array}$} \\
\hline Kontrol & 0,312 & 0,173 & & & \\
\hline
\end{tabular}

Berdasarkan tabel 6 diketahui bahwa setelah dilakukan uji t', skor gain siswa kelas eksperimen dan kelas kontrol memenuhi kriteria $t_{\text {hitung }}>t_{\text {tabel }}$ yaitu 2,434>2,02006, yang menunjukkan bahwa Ho ditolak. Hal ini menunjukkan bahwa terdapat pengaruh dari penggunaan bahan ajar tematik terpadu terhadap hasil belajar siswa kelas V SD.

Berdasarkan hasil analisis data yang dilakukan sebelumnya diperoleh kesimpulan bahwa dengan menggunakan bahan ajar tematik terpadu pada kelas eksperimen dan tidak menggunakan bahan ajar tematik terpadu pada kelas kontrol menunjukkan bahwa adanya pengaruh antara dua kelas yaitu siswa di kelas eksperimen mendapat hasil yang lebih baik daripada siswa di kelas kontrol, karena pembelajaran dengan menggunakan bahan ajar tematik terpadu memungkinkan siswa untuk memahami konsep dengan mudah dan melibatkan siswa secara aktif dalam pembelajaran.

\section{KESIMPULAN}

Penelitian ini mempunyai kesimpulan bahwa adanya pengaruh penggunaan bahanajar tematik terpaduterhadap peningkatan identitas bangsa siswa kelas V SD 20 Indarung. Analisis tes hasil belajar, nilai rata-rata kelas eksperiment lebih tinggi yaitu 78,182 dari kelas kontrol yaitu 67,727 . Berdasarkan analisis uji T pada taraf 0,05 diperoleh $t_{\text {hitung }}=2,434$ dan $t_{\text {tabel }}=2,0200$ Ini artinya $\mathrm{t}_{\text {hitung }}>\mathrm{t}_{\text {tabel }}, \mathrm{H}_{0}$ ditolak dan $\mathrm{H}_{1}$ diterima. Dengan demikian, penggunaan bahan ajar tematik terpadu ini berpengaruh pada identitas 

bangsa siswa SD.

\section{DAFTAR PUSTAKA}

Daryanto dan Dwicahyono, Aris. (2014). Pengembangan Perangkat Pebelajaran (Silabus, Pembelajaran, PHB, Bahan Ajar). Yokyakarta: GavaMedia.

Kantun , S dan Budiawati, Y. (2015). Analisis Tingkat Kelayakan BahanAjjar Ekonomi Yang Digunakan Oleh Guru Di SMA Negeri 4 Jember. Jurnal Pendidikan Ekonomi, Vol.9, no.2 Mei 2015 (129146).

Majid, A. (2014). Strategi

Pembelajaran, Bandung: PT Remaja Rosdakarya.

Mulyasa. (2013). Pengembangan dan Implementasi Kurikulum 2013. Bandung: PT Rosda Karya

Parji. (2011). Pengembanan Nilai-NilaiIntgritas Dan Identitas Nasional Dari Perspektif Pendidikan.JurnalSejarah dan Pembelajarannya.1(2).

Prastowo, i. (2013). Pengembangan Bahan Ajar Tematik. Jogjakarta: Diva Press. 